\title{
“Todo” em Contextos Coletivos e Distributivos
}

(The Brazilian Portuguese Quantifier "Todo" in Distributive and in Collective Contexts)

\author{
Ana Lúcia de Paula MülLeR \\ Esmeralda Vailati Negrão \\ (Departamento de Lingüística da Faculdade de Filosofia, \\ Letras e Ciências Humanas da Universidade de São Paulo) \\ Ana Paula Quadros Gomes
}

(Doutoranda do Departamento de Lingüística da Faculdade de Filosofia, Letras $e$ Ciências Humanas da Universidade de São Paulo - PG-Ling/FFLCH/USP)

ABSTRACT: "Todo" may take a Noun Phrase, a singular or a plural Determiner Phrase as its argument. "Todo" quantifies over parts of its restriction and its nuclear scope and it relates these two "parts'. A sentence with "todo" will be ungrammatical if either the nominal argument or the predicate is not distributable. That is the case for collective predicates whitout sub-events wich nominal subject cannot be partitioned. Todo $+N P$, on the other hand, never gets a collective reading because the NP is a predicate and does not denote an entity that could be involved in a collective action.

KEY-WORDS: distributivity; collective predicates; quantifiers; "todo".

RESUMO: "Todo" pode tomar um NP (nome nu) ou uma descrição definida (DP) plural ou singular como argumento nominal. Esse quantificador opera sobre partes de sua restrição e de seu escopo nuclear e relaciona um ao outro. Uma sentença com "todo" é agramatical se um de seus argumentos não pode ser distribuído; predicados coletivos sem subeventos e com sujeitos que não apresentam são um exemplo. Predicados com Todo $+N P$ não têm leitura coletiva porque um NP não denota uma entidade mas um predicado, e não pode remeter a um grupo em ação coletiva.

PALAVRAS-CHAVE: distributividade; predicados coletivos; quantificadores; "todo".

D.E.L.T.A., 23:1, 2007 (71-95) 


\section{Introdução}

Este artigo tem por objetivo compreender e explicar a semântica de todo em PB, bem como contribuir para o entendimento da variação encontrada em quantificação nas diversas línguas naturais, dentro do espírito de que a busca por universais semânticos é uma hipótese de investigação produtiva (Matthewson 2001 e Chierchia 1998).

O quantificador todo em Português do Brasil (PB) pode tomar tanto um sintagma nominal nu (NP) (1), quanto um sintagma nominal singular (2) ou um plural (3) como argumento; os dois últimos constituem descrições definidas. Contudo, a interpretação semântica não é a mesma nos três casos. A sentença (1) tem apenas uma interpretação distributiva: uma jangada por família. Já as sentenças (2) e (3) são ambíguas: podem receber tanto interpretações coletivas quanto interpretações distributivas.

Nas leituras coletivas, há uma única jangada para uma família inteira em (2), e há somente uma jangada para o grupo de famílias em (3). $\mathrm{Na}$ leitura distributiva, a sentença (2) significa que cada membro da família construiu sua própria jangada; enquanto a sentença (3) significa que cada família, individualmente, construiu separadamente uma jangada para si.

(1) Toda família construiu uma jangada.

(2) Toda a família construiu uma jangada.

(3) Todas as famílias construíram uma jangada.

Na sentença (1), todo parece equivaler ao quantificador do inglês every - um quantificador universal distributivo ${ }^{1}$. Como se espera de um quantificador distributivo, every não é aceitável com predicados coletivos. Em (3), "sleep well" é um predicado distributivo e a sentença é boa. Já em (4), temos um predicado coletivo, "gather in the hall", e a sentença não é boa. O contraste entre (4) e (5) ilustra esse fato. O comportamento de todo nas senten-

\footnotetext{
* Esta pesquisa foi parcialmente financiada pelo CNPq, a quem agradecemos. Agradecemos também os comentários de A. Kratzer e das assistências do Grupo de Estudos de Semântica Formal e do IV Congresso Internacional da ABRALIN.

1 Sobre every e suas manifestações interlingüísticas, ver Bach, Jelinek, Kratzer \& Partee 1995, e Gil 1995. A análise "clássica” pode ser conferida em Barwise \& Cooper 1987 e em Montague 1973, entre outros autores. Não estamos afirmando que todo $+N P$ e every $+N P$ sejam sempre equivalentes (vide Negrão 2002 e Quadros Gomes 2004).
} 
ças (2) e (3), no entanto, é bem mais parecido com o do quantificador all do inglês. All pode ser distributivo (ver (6)), mas também permite leituras coletivas (ver (7)). All é geralmente analisado como um quantificador distributivo, também capaz de distribuir partes de um evento. A diferença entre every e all é atribuída ou bem ao seu significado no léxico ou bem ao tipo de predicado que all seleciona (cf. Link 1983, Dowty 1986 e Taub 1989).

(4) Every student slept well.

todo estudante dormiu bem

Todo estudante dormiu bem.

(5) *Every student gathered in the hall.

todo estudante reuniu em o hall

*Todo estudante se reuniu no hall.

(6) All the students slept well. todos os estudantes dormiram bem Todos os estudantes dormiram bem.

(7) All the students gathered in the hall. todos os estudantes $\mathrm{b}$ reuniram em o hall Todos os estudantes se reuniram no hall.

Neste artigo, defendemos que todo em $\mathrm{PB}$ não é ambíguo entre as interpretações tipicamente obtidas a partir de every e de all, e sim que todo faz a mesma operação em qualquer contexto em que ocorra. A fonte das diferentes interpretações é a variedade de argumentos nominais que todo toma. As diferentes interpretações de sentenças com todo decorrem das diferenças entre as denotações de seus argumentos em cada caso. Defendemos que todo é um quantificador universal distributivo que quantifica sobre partes tanto de sua restrição quanto de seu escopo nuclear. Diferentemente de every, todo pode tomar uma descrição definida como argumento, o que afeta a partição em átomos ou eventualidades das denotações em sua restrição e em seu escopo nuclear.

Este artigo está organizado da seguinte forma: na seção II, apresentamos a descrição dos fatos relevantes sobre a distribuição e a interpretação do quantificador todo em PB. A seção III apresenta a proposta de Link (1983) para o quantificador all do inglês, para confrontá-la com os dados 
de todo em PB. Na seção IV, apresentamos e avaliamos a abordagem de Dowty (1986) para all, discutindo seus problemas e suas vantagens sobre a de Link, em relação aos dados do $\mathrm{PB}$. Na seção $\mathrm{V}$, introduzimos análise de Taub (1989), que explica a (a)gramaticalidade de all em algumas sentenças com predicados coletivos em termos de sua Aktionsarten. Essa abordagem é comparada às de Link e Dowty, e confrontada com os dados. A nossa análise de todo é apresentada na seção VI. Por fim, a seção VII sintetiza nossas conclusões.

\section{Os Fatos}

Nesta seção, apresentamos os fatos concernentes ao quantificador todo em PB mais relevantes para a nossa discussão. O comportamento de todo $+N P$ e o de todo $+D D$ em sentenças com predicados distributivos são discutidos em 1. A seção 2 discute o comportamento dos sintagmas todo $+N P$ e o de todo $+D D$ em contextos de predicação coletiva. Uma generalização descritiva sobre as três formas de sintagma que ocorreu com todo pode entrar é a de que há sempre algum tipo de distributividade universal envolvido nas sentenças de que todo participa.

\section{O comportamento de "todo" em sentenças com predicados distributivos}

Começamos por examinar o comportamento de todo com predicados distributivos do tipo de "dorme bem". Como foi adiantado na introdução, todo $+N P$ tem sempre uma leitura universal distributiva. O significado da sentença (8a) é, então, consistentemente expresso pela forma lógica "clássica” da quantificação universal em (8b). O universal quantifica sobre os membros do conjunto denotado por 'família'. Interessantemente, verificamos que, neste caso, tanto all quanto every são glosas apropriadas para a sentença $(8 a){ }^{2}$

(8) a. Toda família dorme bem.

'Every family sleeps well' / 'All families sleep well'

b. $\square$ x (família’ x 0 dorme.bem’ x)

\footnotetext{
2 Para simplificar, tempo, aspecto e quantificação sobre eventos deixaram de ser representados na forma lógica apresentada neste artigo, a menos que isso fosse necessário.
} 
Por outro lado, não há como traduzir as sentenças (9a) ou (10a) com uma descrição definida (DD) singular, tais como se apresentam em suas estruturas de superfície, para a forma lógica "clássica”. Não há um só constituinte nessas sentenças que possa preencher a primeira parte da implicação lógica. Não há predicados que possam ser tomados como argumento pelo quantificador todo. Descrições definidas denotam entidades, não conjuntos - DDs não são predicados. 'A família', na sentença (9a), denota uma entidade atômica (coletiva). E 'o sofá', em (10a), denota uma entidade atômica.

(9) a. Toda a família dorme bem.

(10) a. Todo o sofá ficou molhado.

A distributividade de todo + singular $D D$ só emerge quando se olha o que está escondido por trás da denotação imediata dos DPs definidos que são seus argumentos. Intuitivamente, (11a) e (12a) podem ser parafraseados como, respectivamente, por 'Cada membro da família dorme bem' e 'Cada parte do sofá ficou molhada'. Essa correspondência é expressa nas formas lógicas em (11b) e (12b).

(11) a. Toda a família dorme bem.

b. $\square$ x (membro.da.família' x 0 dorme.bem x)

(12) a. Todo o sofá ficou molhado.

b. $\square \mathrm{x}$ (parte.do.sofá x 0 ficou.molhado x)

O mesmo pode ser dito a respeito das sentenças (13a) e (14a), em que todo toma uma descrição definida plural como argumento. DDs plurais denotam entidades plurais, não predicados. 'As famílias', em (12a), denota uma entidade plural, que é uma soma de todas as famílias relevantes (cf. Link 1983). Isso também é verdadeiro para 'as crianças', que denota um indivíduo plural, que não é nada além de uma soma de todas as crianças relevantes. Podemos descrever esses plurais individuais tanto como um grupo de famílias quanto um grupo de crianças. Esses DDs são argumentos, e não predicados - assim sendo, como eles podem proporcionar um conjunto de indivíduos sobre o qual todo possa quantificar?

(13) Todas as famílias dormem bem.

(14) Todas as crianças dormem bem. 
As sentenças (13) e (14) podem ser parafraseadas, respectivamente, como 'Cada família dorme bem' e 'Cada criança dorme bem'. Essas equivalências são expressas pelas formas lógicas em (15b) e (16b). É importante notar que não há, em nenhuma das duas sentenças, um constituinte que possa corresponder à primeira parte da forma lógica em (15b) e (16b). Os constituintes singulares 'família' e 'criança' não ocorrem nas sentenças em questão. Mais uma vez, vemos que a origem da distributividade só aparece quando o quantificador opera sobre as partes do indivíduo denotado pela descrição definida, neste caso, sobre os átomos que compõem o indivíduo plural.

(15) a. Todas as famílias dormem bem.

b. $\square$ x (family' x 0 sleep.well x)

(16) a. Todas as crianças dormem bem.

b. $\square \mathrm{x}$ (child' x 0 sleep.well' $\mathrm{x}$ )

Nesta seção, vimos que todo, quando ocorre com predicados distributivos, é sempre um quantificador universal distributivo. A distributividade de todo $+D D$ emerge sempre que todo pode operar sobre as partes da entidade denotada pela DD (singular ou plural).

Entretanto, vários mistérios permanecem sem solução. Em termos sintáticos, todo aparentemente seleciona diferentes tipos de argumentos - ora um NP, ora um sintagma de determinante (DP). Em termos semânticos, todo aparentemente é capaz de transformar a entidade que toma por argumento num predicado, num conjunto feito de partes daquela entidade. $\mathrm{Na}$ próxima seção, examinaremos o comportamento de todo com predicados coletivos.

\section{O comportamento de todo com predicados coletivos}

O comportamento contrastante de todo $+N P$ em predicados distributivos versus predicados coletivos emerge com muita clareza com predicados que podem ser tanto distributivos quanto coletivos, como "construir uma jangada". A sentença (17), com todo $+N P$, tem exclusivamente interpretação distributiva, e a leitura é a de um evento de construção de jangada por família (17b). A leitura coletiva, em que haveria um único evento de construção de jangada para o conjunto de todas as famílias (17c), não é possível. 
(17) a. Toda família construiu uma jangada.

b. $\square$ x (família' x $0 \square y$ (jangada' y $\square$ construiu' $x, y)$ )

c. * $\square \mathrm{y} \square \mathrm{x}$ (família' x $\mathrm{O}$ (jangada' y $\square$ construiu’ x,y))

Todo + Descrição Definida, por outro lado, comporta-se como all. A sentença com todo + singular $D D$ (18a) tem tanto uma interpretação coletiva - uma jangada para a família inteira (18b) - quanto uma leitura distributiva menos proeminente - uma jangada para cada membro da família (18b).

(18) a. Toda a família construiu uma jangada.

b. $\square y \square x$ (membro.da.família' x 0 (jangada' y $\square$ construiu’ x,y))

c. $\square$ x (membro.da.família' x 0 四y (jangada' x $\square$ construiu’ x,y))

A sentença com todo $+D D$ plural (19a) é também ambígua entre a interpretação distributiva, em que cada família construiu sua jangada (19b), e a coletiva, em que as famílias, reunidas, construíram uma única jangada (19c).

(19) a. Todas as famílias construíram uma jangada.

a. $\square$ x (família' x $0 \square y$ (jangada' $x \square$ construiu' $x, y)$ )

b. \y $\square \mathrm{x}$ (família' $\mathrm{x} 0$ (jangada' y $\square$ construiu' $\mathrm{x}, \mathrm{y})$ )

Na próxima seção, vamos examinar mais detalhadamente as leituras coletivas com todo. O que aflora nesse exame é que, mesmo nas leituras coletivas de todo $+D D$, algo acaba sendo distribuído.

\section{A Proposta de Link}

Nesta seção, apresentamos abordagem de Link para a semântica do quantificador do inglês all, e examinamos como ela se aplica aos dados das sentenças com todo do PB.

Link (1983) desenvolve uma teoria de plurais na qual estabelece uma relação entre um predicado singular como 'família' e seu plural 'famílias'. Ele faz uso de semi-reticulados e da relação "ser parte de" (part of relation, d). $\mathrm{Na}$ teoria de Link, a denotação do nome comum é feita de átomos. A denotação de 'família', num mundo com apenas três famílias, é uma estru- 
tura como a representada em (20), que contém tanto átomos quanto moléculas. Já a denotação do nome plural 'famílias' está representada, em (21), para um mundo com três famílias. Ela contém tanto átomos quanto moléculas.

(20) $[$ [família $]=\quad$ a $\quad$ b $\quad c$

(21) Denotação de famílias, para um mundo com três famílias

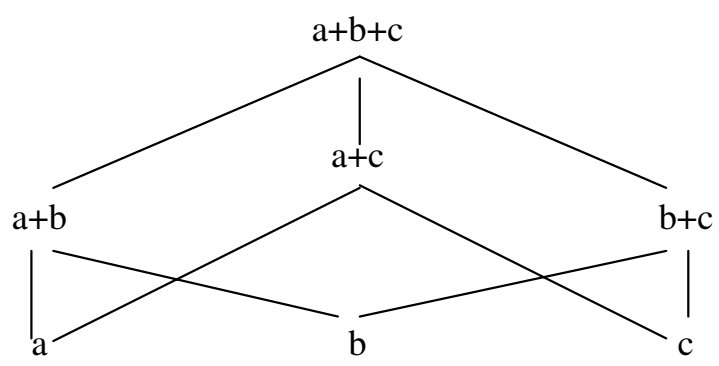

Predicados coletivos são inerentemente incompatíveis com sujeitos atômicos. Portanto, qualquer operação que simplesmente distribua um dado predicado coletivo sobre átomos deve conduzir a um resultado agramatical. A distribuição de predicados coletivos com os quantificadores every ou each mostra exatamente esse comportamento: o predicado original é distribuído, e o resultado é a agramaticalidade atestada em (22-23).

(22) *Every student gathered in the hall.

(23) *Each student gathered in the hall.

Como vimos antes, predicados coletivos do tipo de gather in the hall ou built the raft podem combinar-se com all (vide 24-27). ${ }^{3}$ Para poder manter que all é um quantificador universal distributivo, como indica o seu comportamento com predicados distributivos, Link propõe uma tradução de all que introduz um predicado distributivo relacionado ao predicado coletivo original e que significa algo próximo de "tomar parte em" ("take part in"). A sentença (24), então, segundo Link, equivale aproximadamente a (25).

Link (1983) trabalha apenas com all $+D D$ plural. 
(24) All the students built the raft. Todos os estudantes construíram a jangada. "Todos os estudantes construíram a jangada"

(25) Os estudantes construíram a jangada e cada estudante tomou parte na construção da jangada.

Segundo Link, a exata natureza da relação entre os predicados coletivos e a relação "tomar parte em" precisa ser deixada em aberto. Ela é determinada por propriedades extralingüísticas do mundo. A única coisa que precisa se manter para cada membro do grupo é ele ter feito algo que seja considerado tomar parte no vento denotado pelo predicador.

Em suma, Link formaliza all como um quantificador distributivo universal sobre elementos atômicos do sujeito plural. Mas, já que a distributividade sobre átomos é imprópria com predicados coletivos de grupo, Link postula o operador 'tomar parte em', que deriva um predicado distributivo de cada predicado coletivo e é parte da tradução de all.

A proposta de Link descreve adequadamente a interpretação de predicados coletivos em sentenças do PB com todo $+D D$ plural. De acordo com ela, a sentença (26a), parafraseada como (26b), tem a forma lógica em (26c). (26c) diz que todas as famílias, como um grupo, construíram a jangada, e que cada família, individualmente, de um modo ou de outro, tomou parte na construção da jangada. Note que, para Link, o DD plural denota a soma máxima (contextualmente determinada) na denotação do nome plural 'famílias' ( $a+b+c$ em (21)). Nas nossas ilustrações (20-21), os átomos de 'as famílias'são as famílias individuais a, b e c.

(26) a. Todas as famílias construíram a jangada.

b. As famílias construíram a jangada e cada família tomou parte na construção da jangada.

c. construíram.a.jangada' (as.famílias') $\square \square$ x (x d as.famílias' 0 tomaram.parte.na.construção.da.jangada' $x$ )

Link não faz menção a ocorrências de all com descrições definidas singulares, mas, com as devidas adaptações, sua análise dá conta de todo $+D D$ singular em sentenças de predicado coletivo como (27a), parafraseada em (27b). A forma lógica correspondente, (27c), diz que a família construiu a balsa, e que cada membro da família, individualmente, tomou parte na construção da balsa. O problema formal com (27c) é que os membros da 
família denotada pela DD "a família” em (27a) não são átomos segundo a definição de Link's. Visto que a DD "a família" denota, por si mesma, um átomo, os membros da família são, se quisermos levar adiante a metáfora atômica, subatômicos, por assim dizer. Recordamos que descrições definidas singulares denotam o único membro da classe (em um certo contexto).

(27) a. Toda a família construiu a jangada.

b. A família construiu a jangada e cada membro da família tomou parte na construção da jangada.

c. construir.a.jangada' (a.família') $\square \square \mathrm{x}$ (membro.da. família' xO tomar.parte.na.construção.da.jangada' x)

Será que essa análise poderia explicar a agramaticalidade de todo $+N P$ com predicados coletivos? A sentença (27a) não tem leitura coletiva. Não pode ser compreendida como descrevendo um único evento de construção de uma única jangada por uma família determinada. Além da leitura distributiva mais saliente, segundo a qual temos uma balsa por família, (27a) pode ter uma interpretação distributiva iterativa segundo a qual a mesma jangada é (re-)feita outra vez e outra vez. Deixaremos de lado essa última leitura, por enquanto.

Os problemas começam ao tentarmos parafrasear (28a) conforme a proposta de Link, como foi feito em (27) para todo $+D D$ plural - não existe uma entidade tal que se possa afirmar das partes dessa entidade (ou de seus membros) que elas (eles) tomaram parte na eventualidade denotada pelo predicado. "Toda família", em PB, distribui sobre famílias individuais e não sobre membros destacados de uma certa família. De um jeito ou de outro, "família" nunca denota uma família em particular. Poderia ser dito que denota o nome de espécie 'família' (ver Mathewson 2001 para o inglês). Esse passo em nada nos ajudaria presentemente, entretanto, dado que não pode ser dito da sentença (28a) que exista quantificação sobre tipos de família. Conseqüentemente (28b), em nenhuma das versões, é uma paráfrase possível para (28a), e (28c) não é uma forma lógica possível para uma leitura coletiva de (28a).

(28) a. Toda família constrói a jangada.

b. !*Família constrói a jangada e cada membro de família toma parte na construção da jangada.

c. construir.a.jangada' (família' x) $\square \square$ x (membro.da.família’ xO

tomar.parte.na.construção.da.jangada' $x$ ) 
Para o momento, vamos provisoriamente concluir que a análise de Link para all não provê uma explicação adequada sobre a agramaticalidade de todo $+N P$ em predicados coletivos. Se a adotássemos, seríamos forçados a postular que o quantificador todo é ambíguo entre dois significados: um, a correspondente ao do inglês every; e o outro, o correspondente ao de all.

Cabe perguntar como a teoria de Link daria conta das leituras distributivas de todo $+D P$ e de todo $+N P$. Segundo Link, leituras distributivas são o resultado da aplicação de um operador $\mathrm{D}$ (istributivo) implícito. Esse operador introduz uma quantificação universal sobre a denotação do sujeito, como ilustrado para o inglês, em (29). A forma lógica em (29b) diz que, agora, o predicado ${ }^{D}$ sleep.well', recém-transformado em distributivo, corresponde a uma quantificação universal sobre os átomos do sujeito (29c).

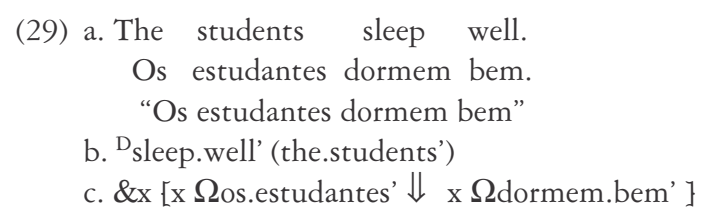

No entanto, (29a) não é exatamente um sinônimo de (30). A diferença entre as sentenças é que (30) requer que cada aluno, sem exceção, durma bem, ao passo que a afirmação de (29) é mais fraca, permitindo exceções. Podemos concluir que o efeito de all num predicado distributivo, chamado de "Efeito de Maximalidade" (Maximizing Effect) em Dowty 1986 é, então, o de causar uma interpretação máxima do sujeito.

(30) All the students sleep well.

Determinar o que é que permite a não-maximalidade em uma sentença com predicado distributivo plural é algo que está além do escopo deste artigo. ${ }^{4} \mathrm{O}$ que queremos ressalvar é que a análise de Link para all pode ser aplicada a sentenças de predicação distributiva com todo $+D D$. A lógica de (31b) é correspondente à de (31c) porque alguém só pode tomar parte numa atividade de dormir bem se essa pessoa, individualmente, dormir bem. Os dois lados da conjunção são sinônimos. Assim sendo, se assumi-

4 Mas veja Dowty 1986, Schwarchild 1996 e Brisson 2003 sobre análises da distributividade e do Maximizing Effect. 
mos a análise de Link, temos que a distributividade de all é redundante com predicados distributivos e que, nesse caso, seu papel é exclusivamente o de acionar o Efeito de Maximalidade. Isso fica visível ao comparamos (31b) a (31c), em que a primeira sentença, ${ }^{D}$ dormir.bem', foi substituída por sua fórmula equivalente. (31c) afirma que cada átomo na denotação de os estudantes dormiu bem, e que cada um desses átomos tomou parte no ato de dormir bem.

(31) a. Todos os alunos dormiram bem.

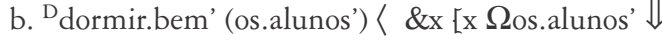
tomar.parte.em.dormir.bem' $\mathrm{x}]$

c. $\square \mathrm{x}$ [x d os.alunos' o x d dormir.bem'] $\square$ x [x d os.alunos' o tomar.parte.em.dormir.bem' $\mathrm{x}]$

A mesma análise pode ser proposta para todo $+D D$ singular em sentenças de predicação distributiva como (32a) em PB, desde que seja desconsiderado o problema formal de lidar formalmente com as partes subatômicas de entidades. A primeira parte da conjunção em (32b) expressa a forma lógica de $A$ família dorme bem, e deveria, de um modo ou de outro, permitir que alguns, entre os membros da família, não necessariamente tivessem de dormir bem para que a sentença fosse feliz. A segunda conjunção garante que todo e qualquer membro da família dorme bem. Logo, (31b) expressa bem as condições de verdade de uma sentença distributiva com todo $+D D$ singular.

(32) a. Toda a família dormiu bem.

b. ' dormir.bem' (a.família') $\square \square \mathrm{x}$ (membro.da.família' $\mathrm{x} \emptyset$ tomar.parte.em.dormir.bem' $\mathrm{x}$ )

Outra vez, temos um problema quando tentamos utilizar essa análise para todo $+N P$ com predicados distributivos. 'Família', um nome comum, não é um argumento adequado para um predicado distributivo. E não existe nenhuma relação parte-todo a ser estabelecida, por não existir uma entidade denotada pelo argumento de todo que possa ser particionada.

(33) a. Toda família dorme bem.

b.? Dormir.bem' (família') —? ? x (parte.da.família' x 0 tomar.parte.em.dormir.bem' $\mathrm{x}$ ) 
A proposta de Link é insatisfatória em alguns aspectos. Primeiramente, apesar de funcionar bem para todo $+D D$, ela nos força a assumir a existência de dois todos: de um lado, um quantificador distributivo muito semelhante a every, e, de outro, um quantificador universal distributivo com a propriedade lexical de ser capaz de distribuir sobre as partes subatômicas de seu sujeito. Em segundo lugar, o fato de all causar um Efeito Maximizador em sentenças com predicados distributivos não apresenta relação com a distribuição sobre partes do evento que esse quantificador provoca em sentenças com predicados coletivos.

A próxima seção é uma incursão na abordagem de Dowty sobre os fatos do comportamento de all em contextos de predicação coletiva. Veremos que all é gramatical com alguns, mas não com quaisquer predicados coletivos.

\section{A Proposta de Dowty}

Dowty 1986 concorda com Link sobre all ser um quantificador distributivo universal, e atribui a ele o Efeito Maximizador. Não obstante, o comportamento de all com predicados coletivos não é atribuído ao seu significado lexical, mas ao fato de que alguns desses predicados apresentam subacarretamentos distributivos como parte de seus significados. A proposta de Dowty é capaz de explicar por que all é compatível com certos predicados coletivos, mas não com todos. Ela também dá conta de explicar a razão pela qual algumas das ocorrências de all não são distributivas nos termos de Link.

Como vimos nas seções anteriores, all é compatível com predicados coletivos. Dowty mostra que, ainda que isso valha para muitos predicados coletivos, há casos de predicação coletiva que não são compatíveis com all. Os exemplos de Dowty são paralelos às traduções para o PB com o todo + pluralDD, que é agramatical com "predicados de pura cardinalidade" (34-35), e também com as interpretações coletivas do tipo de "predicados coletivos aditivos" (36) (cf. Dowty 1986).

(34) a. Os alunos formam um grupo grande.

a. *Todos os alunos formam um grupo grande.

(35) a. Os coalas são numerosos na Austrália.

a. *Todos os coalas são numerosos na Austrália. 
Como visto, há casos em que o acréscimo de todos $+D D$ a uma predicação coletiva resulta em agramaticalidade (34-35). Não obstante, a aceitabilidade de coletivos como em (36) com todos $+D D$ é um contra-exemplo para a teoria de que todos seja compatível exclusivamente com (alguma espécie de) predicação coletiva, como Link defende. (36c) não é uma boa paráfrase de (36b), ao contrário do que a proposta de Link prediz.

(36) a. Os estudantes se reuniram na sala

b. Todos os estudantes se reuniram na sala.

c. ?? Todos os estudantes se reuniram na sala e cada estudante tomou parte em se reunir na sala.

Para dar conta desses fatos, Dowty afirma que alguns predicados coletivos contêm subacarretamentos que se aplicam a indivíduos ("distributive sub-entailments") mesmo quando sua interpretação primária é coletiva. Esse ponto fica patente na forma como Dowty explica a gramaticalidade da sentença em inglês equivalente a (36b):

"Considere os requisitos para que [a sentença] The students gathered in the hall seja verdadeira. Obviamente, cada estudante do grupo referido por the students deve vir até o hall e permanecer ali o suficiente para que seja possível a todos estarem presentes no local em um mesmo período."

Para Dowty, o que all faz é introduzir um quantificador universal que distribui subacarretamentos sobre cada indivíduo do sujeito plural. A vantagem de Dowty sobre Link é que, ao situar os meios para a distributividade, os subacarretamentos, nos predicados, em lugar de localizá-los em all, permite que a combinação de all com alguns predicados coletivos redunde agramatical. A explicação para a agramaticalidade resultante da adição de all a certas sentenças de predicado coletivo é que o predicado em questão não apresenta subacarretamentos.

Todo $+D D$ singular se comporta exatamente do mesmo modo que todo + DD plural. Redunda em agramaticalidade com "predicados de pura cardinalidade" (37-39), mas é gramatical com predicados coletivos que apresentam subacarretamentos (40).

\footnotetext{
"Consider what is required for The students gathered in the hall to be true. Clearly, every student in the group referred to by the students must come into the hall and remain long enough that they are all there at a common time." (tradução nossa).
} 
(38) a. A família forma um grupo grande

b. *Toda a família forma um grupo grande.

(39) a. A família Müller é numerosa na Austrália.

b. *Toda a família Müller é numerosa na Austrália.

(40) a. A família se reuniu no hall.

b. Toda a família se reuniu no hall.

A análise de Dowty explica o porquê de todo ser compatível com alguns, mas não com quaisquer predicados coletivos. Sua análise localiza a fonte da (in)compatibilidade com predicados coletivos na semântica dos próprios predicados. A desvantagem da análise de Dowty reside no fato de que ela não oferece uma explicação baseada em princípios independentes para predizer se um ou outro predicado apresentará ou não subacarretamentos. A única forma de verificar se um predicado coletivo é do tipo que contém subacarretamentos é ver se ele forma sentenças gramaticais ou agramaticais com all como sujeito. A análise também não nos ajuda a lidar com os fatos de todo $+N P$.

Na próxima seção, vamos nos voltar para a abordagem de Taub's (1989) sobre a semântica de all. Ela mostra que a classe aspectual dos predicados é relevante para a predição da (a) gramaticalidade de uma sentença de predicado coletivo com all.

\section{A Proposta de Taub}

Taub (1989) faz uso das classes aspectuais de Vendler (1967) para explicar a incompatibilidade de alguns predicados coletivos com all. Vendler propõe quatro categorias de aktionsarten: estados, atividades, accomplishments e achievements. Estados são predicados próprios de sujeitos que permanecem imutáveis no decorrer do tempo. Atividades são desempenhadas uniformemente pelo sujeito durante toda a sua duração. Accomplishments são atividades que conduzem a um ponto de culminância. $\mathrm{E}$ achievements denotam o estado final, o momento de culminância, sem incluir qualquer ação que tenha conduzido àquele resultado.

Taub mostra que aqueles predicados coletivos que não permitem um sujeito com all são membros ou da categoria estado ou da categoria achievement. Inversamente, os predicados coletivos compatíveis com all são aqueles que podem ser classificados como atividades ou accomplishments. 
O comportamento das classes de aktionsarten com o tempo progressivo é utilizado por Taub para comprovar essa tese para o inglês. Estados são incompatíveis com o tempo progressivo. Atividades e accomplishment são as classes de predicado que se combinam bem com o progressivo. Achievements são incompatíveis com o tempo progressivo, a menos que o progressivo seja parafraseado pelo progressivo futuro "is going to".

As sentenças (41-42) mostram que os estados coletivos são agramaticais com o progressivo. As sentenças (43-44) mostram que as atividades coletivas e os accomplishments são perfeitos com o progressivo. Finalmente, as sentenças (45-46) mostram que os achievements coletivos no tempo progressivo mudam de aktionsart e as sentenças passam a ser interpretadas como atividades - essas sentenças só podem ser interpretadas como predicados distributivos.

(41) *Os jogadores estão sendo um time vitorioso.

(42) *Os coalas estão sendo numerosos na Austrália.

(43) Os estudantes estão se reunindo no hall.

(44) As crianças estão construindo a jangada/uma jangada.

(45) \#Os senadores estão aprovando por unanimidade a emenda.

(46) \# Os eleitores estão elegendo por unanimidade um presidente.

Um padrão emerge: aqueles predicados coletivos que não permitem todo + DD plural como sujeito são ou do tipo achievement ou do tipo estado. Entre os predicados coletivos, aqueles que são do tipo atividade ou accomplishment podem ocorrer com todo (49-50). Esses são predicados que contêm um componente de "atividade". Os estados coletivos (47-48) e achievements (51-52), que não dispõem desse traço de atividade, são incompatíveis com todo.

(47) *Todos os jogadores são um time vitorioso.

(48) *Todos s coalas são numerosos na Austrália.

(49) Todos os estudantes se reúnem no hall.

(50) Todas as crianças construíram a jangada/uma jangada.

(51) \# Todos os senadores aprovaram por unanimidade a emenda.

(52) \# Todos os eleitores elegeram por unanimidade um presidente.

O mesmo padrão vale para todo $+D D$ singular. Os estados coletivos são incompatíveis com todo $+D D$ singular (53-54). predicados coletivos que denotam atividades ou accomplishments são perfeitos com todo $+D D$ 
singular (55-56). Por fim, coletivos da classe achievement são agramaticais com todo $+D D$ singular (57-58).

(53) *Todo o time é vitorioso.

(54) *Toda a alcatéia é numerosa na Austrália.

(55) Toda a família se reune no hall.

(56) Toda a família construiu a jangada/uma jangada.

(57) \# Todo o Senado aprovou por unanimidade a emenda. (na leitura coletiva)

(58) \# Todo o eleitorado elegeu por unanimidade o presidente. (na leitura coletiva)

A proposta de Taub tem algumas vantagens sobre a de Dowty. A aktionsarten é um método de classificação de predicados tradicional e independentemente motivado, e fornece um método mais apropriado para identificar os predicados compatíveis com todo. Por esse método, um predicado pode ser identificado independentemente como membro de uma divisão particular da aktionsarten. Assim, parece ser possível separar corretamente os predicados coletivos compatíveis com todo dos predicados coletivos que são incompatíveis com todo.

Taub argumenta que a conexão entre o traço "atividade" a distributividade de all (bem como, podemos emendar, a de todo, já que ambos os quantificadores comportam-se da mesma maneira) reside no fato de atividades serem distributivas em essência. Para Taub, all (bem como todo) é distributivo e requer um a predicado que seja, por sua vez, distributivo ou que, no mínimo, tenha um componente distributivo, para que a sentença seja gramatical.

A abordagem de Taub deixa ainda a descoberto, sem explicação, a ausência de leituras coletivas para todo $+N P$. Na próxima seção, veremos que, diante dos dados, não é possível manter que predicados coletivos sejam, por si mesmos, incompatíveis com todo. A seção seguinte apresenta a nossa análise para a semântica de todo.

\section{Nossa Análise}

Nesta seção, defendemos que todo, em todos os seus contextos e em todas as suas interpretações, é sempre um quantificador universal distributivo, que as leituras coletivas são ilusórias e que o Efeito Maximizador é um subproduto da distributividade de todo. Também defendemos que todo pode 
realizar partições subatômicas nas denotações tanto de sua restrição quanto de seu escopo nuclear.

\section{Todo $+D D$}

Primeiramente, devemos salientar que o decide a gramaticalidade de sentenças com o quantificador todo não é tão-somente o tipo de predicado, mas também a compatibilidade entre a denotação do predicado e a natureza da denotação do argumento nominal de todo. A sentença (59), com todo $+D D$ plural, é um predicado coletivo de estado e é agramatical, tal como prediz a tese de Taub. A sentença (60) é do exatamente do mesmo tipo: um sujeito todo $+D D$ plural combinado a um predicado coletivo de estado. Surpreendentemente, (60) é perfeitamente gramatical. A única diferença entre (59) e (60) é o fato de o nome comum em (60) ser um nome de coletividade.

(59) *Todos os coalas são numerosos na Austrália.

(60) Todas as famílias são numerosas na Austrália.

O mesmo contrate emerge com todo $+D D$ singular. A sentença (61), com um predicado coletivo de atividade e uma descrição definida (DD) singular é agramatical, contrariamente à predição de Taub para all, e por nós aplicada a todo $+D D$ singular. A mesma sentença se torna gramatical se damos ao quantificador todo uma DD que seja um nome de coletividade como argumento nominal (cf. 62).

(61) *Toda a criança se reúne no hall.

(62) Toda a família se reúne no hall.

Os quantificadores podem ser interpretados como gerando estruturas tripartites que estabelecem relações entre uma restrição e um escopo nuclear (Lewis 1975, Kamp 1981, Heim 1982). O significado de uma sentença com todo $+N P$ como, por exemplo, (63a), pode ser descrito pela forma lógica em (63b), que mostra o quantificador tomando dois argumentos. O que o quantificador faz é distribuir a propriedade denotada pelo escopo nuclear sobre cada átomo na denotação de sua restrição. Com uma análise assim, é natural que se fique surpreso quando um predicado 
coletivo coocorre com um quantificador distributivo do tipo de todo. Predicados coletivos, por definição, não poderiam ser distribuídos. Um exemplo disso é (64):

(64) a. Toda criança dorme bem b. toda' $\left[\left(_{\text {Restriçáo }}\right.\right.$ criança'), (

(68) *Toda criança se reuniu na sala.

Contrariamente ao que foi falado anteriormente sobre predicados coletivos, nós defendemos que qualquer predicado pode ser distribuído por todo, desde que a sentença contenha um sujeito de tipo compatível. Não se pode dizer de cada coala que é numeroso, mas pode-se dizer de cada família que ela é numerosa (59 versus 60). A mesma explicação dá conta do contraste entre (61) e (62): não se pode dizer de uma criança individual que ela se reuniu no hall, mas isso pode ser dito de uma família.

Essa generalização funciona perfeitamente no sentido inverso também: não se pode distribuir automaticamente qualquer predicado distributivo. A sentença (65) diz que todas as partes do sofá são pesadas, o que não faz sentido. A sentença (66), por outro lado, diz que todas as partes (ou cada parte relevante) do sofá ficaram molhadas, o que é perfeitamente aceitável e faz sentido.

(65) *Todo o sofá é pesado.

(66) Todo o sofá ficou molhado.

Defendemos que todo é realmente um quantificador distributivo universal: todo estabelece uma relação universal de um para um. O que o distingue de quantificadores como every ou each (ou do cada, do PB) é que todo pode tomar descrições definidas como argumento. Descrições definidas denotam entidades, mas não predicados, e todo pode repartir tais entidades e distribuir sobre suas partes (vide as interpretações de (67) e (68)). O mesmo ocorre com o predicado, que pode ser distribuído como um conjunto de eventualidades singulares (vide (67) e (68)) ou como uma única eventualidade repartida em subeventualidades (vide (69) e (70)).

(67) Todas as crianças dormiram bem.

Interpretação: Um átomo do grupo denotado por 'as crianças' por evento de dormir

(68) Toda a família dormiu bem.

Interpretação: Um átomo da denotação de 'a família' por evento de dormir 
(69) Todas as crianças se reuniram no hall. Interpretação: Um átomo do grupo denotado por 'as crianças' por evento de 'sub-reunir-se'

(70) Toda a família se reuniu na sala. Interpretação: Um membro da denotação de 'a família' por evento de 'sub-reunir-se'

As ambigüidades têm lugar nos casos em que mais de um tipo de relação distributiva é possível. Na sentença (71), pode-se tanto distribuir 'famílias' por eventos inteiros de 'construção' quanto por subeventos de construção incluídos num evento singular de construção. Correspondentemente, na sentença (72), membros de 'a família' podem ser pareados com distintos eventos de construção ou com distintos subeventos incluídos em um único evento de construção da jangada.

(71) Todas as famílias construíram uma jangada. Interpretações Possíveis:

a. uma família por evento de construção de jangada

b. uma família por subevento de construção de jangada

(72) Toda a família construiu uma jangada.

Interpretações Possíveis:

a. um membro da denotação de 'a família' por evento de construção da jangada

b. um membro de 'a família' por subevento de construção da jangada

Concluímos que todo $+D D$ é sempre distributivo, e que as leituras "coletivas" de todo $+D D$ são meras ilusões criadas pela possibilidade de distribuir tanto sobre subpartes do sujeito quanto subpartes do predicado. Essas possibilidades não estão disponíveis para outros quantificadores distributivos.

A seguir, voltamos à questão de por que nunca se obtém uma leitura "coletiva" para sentenças com todo $+N P$.

\section{2. $T o d o+N P$}

Como vimos, uma sentença do tipo de (73) nunca tem uma leitura "coletiva". Não há uma interpretação que distribua sobre os membros da família os subeventos de um único que evento de construção de jangada (vide 73b). E também não há uma leitura de distribuição de distintas famílias sobre subeventos do mesmo evento de construção de jangada (vide 73c). 
(73) Toda família construiu uma jangada. Interpretações possíveis:

a. uma família por evento de construir uma balsa

b. *um membro da família por subevento de construir uma balsa

c. *uma família por subevento de construir uma balsa

Coerentemente com nossa análise, relacionamos a solução do problema ao fato de o argumento de todo ser um NP e não um DP, já que essa é a única diferença encontrada entre as sentenças com todo $+N P$ e as sentenças com todo $+D D$. Postulamos que não há, em todo $+N P$, um constituinte que denote uma entidade singular, e, na ausência de uma entidade singular, não há nada que possa ser dividido em subpartes.

\section{Quantificação e Variação Interlingüística}

Assumimos a visão, inspirada em Matthewson (2001), de que quantificadores podem tomar sintagmas de determinante (Determiner Phrases, DPs) como seu primeiro argumento. Conseqüentemente, a geração de um sintagma quantificado (QP, de Quantifier Phrase) pode envolver dois passos: o primeiro é a criação de um DP, e o segundo envolve quantificação sobre partes da entidade denotada pelo DP. A estrutura composicional dessas operações é ilustrada em (74). Intuitivamente, o que o primeiro passo faz é restringir o domínio sobre o qual a quantificação ocorrerá.

(74) “Toda(s) a(s) família(s)” segundo o modelo de Matthewson (2001)

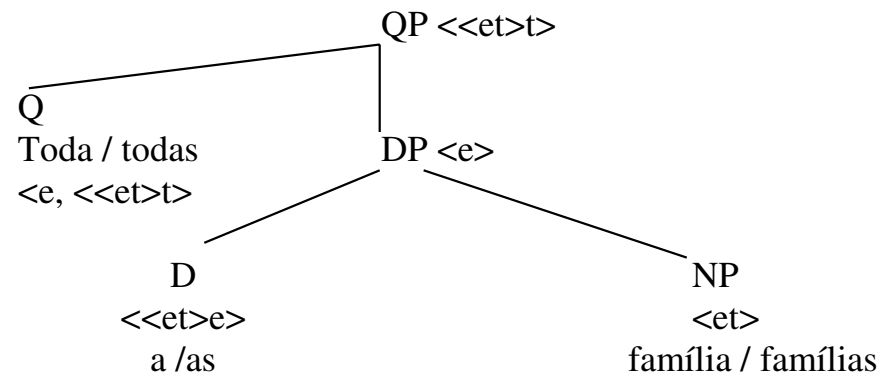


A estrutura em (74) difere da análise "clássica" de QPs (vide Montague 1973 e Barwise \& Cooper 1887, entre outros). Na análise "clássica", quantificadores generalizados tomam NPs (predicados) como argumentos, como ilustrado em (75). Como se pode constatar, em (75) não há um constituinte que denote uma entidade que sirva, numa operação posterior, de indivíduo a ser repartido pelo quantificador. Conseqüentemente, o quantificador só pode quantificar sobre a denotação do NP, a qual já é inerentemente dividida em partes. Se assumirmos que NPs denotam conjuntos de átomos, o QP toda+família, por exemplo, irá quantificar sobre crianças atômicas, mas nunca sobre partes de alguma criança ou sobre grupos de crianças.

(75) “Toda família” segundo a análise "clássica” de quantificação nominal

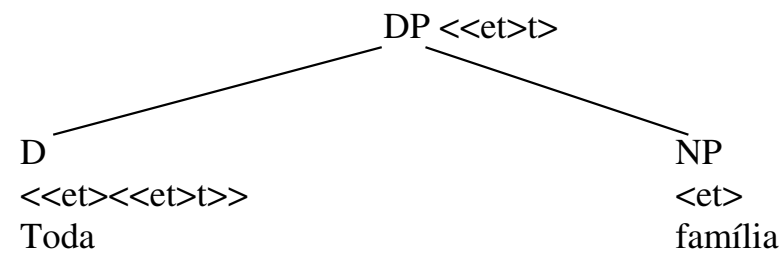

Já podemos voltar à leitura iterativa de (76). O que acontece ali é a distribuição de eventos de construção da mesma jangada, um para cada família. A única forma de interpretar a sentença é entendendo que uma mesma jangada foi refeita várias vezes, já que há uma única jangada disponível.

(76) Toda família constrói a jangada.

Concluímos que leituras "coletivas" nunca estão disponíveis para todo $+N P$ porque NPs nunca denotam indivíduos plurais ou grupos, mas sempre denotam conjuntos de entidades. Logo, nunca há um indivíduo ao qual possa ser atribuída uma predicação coletiva. DDs, por outro lado, denotam entidades atômicas ou plurais, e tais entidades podem ser interpretadas como sujeitos de predicação coletiva (ou criar a ilusão de existência de uma predicação coletiva). 


\section{Síntese e Conclusões}

Percorremos os pontos relacionados à semântica do quantificador todo em contextos de predicação distributiva e em contextos de predicação coletiva. Foram avaliadas distintas propostas da literatura para o quantificador inglês all - a de Link (1983), a de Dowty (1986) e a de Taub (1989). Todas elas assumem que all é um quantificador universal distributivo em sentenças de predicação distributiva. Elas se diferenciam quanto à explicação que oferecem para o fato de que all é gramatical em (certos) contextos coletivos.

Essas abordagens não foram examinadas somente naquilo que concerne ao correlato de all no $\mathrm{PB}$, todo $+D D$ plural, mas também quanto aos fatos de todo $+D D$ singular e de todo $+N P$ em $\mathrm{PB}$. As abordagens dão conta dos fatos que emergem em contextos distributivos. Mas, em contextos coletivos, elas se coadunam com os fatos de todo $+D D$, mas não explicam o comportamento de todo $+N P$.

Mostramos que, contrariamente a essas abordagens, para a gramaticalidade de sentenças quantificadas com todo não basta controlar o tipo de predicado, pois o tipo de sujeito também influi. Todo é sempre um quantificador universal distributivo, e seu significado inclui a capacidade de distribuir sobre partes de seu argumento nominal e de seu predicado. As diferenças de compatibilidade emanam da estrutura interna tanto da restrição quanto do escopo nuclear do quantificador. Nossa análise tem as vantagens de: (1) não propor qualquer ambigüidade para o quantificador todo; e (2) de derivar composicionalmente os efeitos desse quantificador em distintos contextos.

Recebido junho de 2005 Aprovado em fevereiro de 2007

E-mail: anamuler@usp.br

\section{REFERÊNCIAS BIBLIOGRÁFICAS}

Bach, E. , E. Jelinek, A. Kratzer \& B. Partee 1995. Quantification in Natural Languages. Dordrecht/Boston/London: Kluwer. 
Barwise, J. \& R. Cooper 1987. Generalized Quantifiers and Natural Language. Linguistics and Philosophy 4:159-219.

Brisson, C. 2003. Plurals, All, and the Nonuniformity of Collective Predication. Linguistics and Philosophy 26: 129-184.

Chierchia, G. 1998. Reference to Kinds across Languages. Natural Language Semantics 6: 339-405.

Doetjes 1979. Quantifiers and Selection. On the Distribution of Quantifying Expressions in French, Dutch and English. Ph.D dissertation, Leiden University.

Dowty, D. 1986. A Note on Collective Predicates, and All. In F. Marshall, ed. Proceedings of the Third Eastern States Conference on Linguistics (ESCOL): 97-115.

GIL, D. 1995. Universal Quantifiers and Distributivity. In E. BACH, E. Jelinek, A. Kratzer \& B. Partee, eds. 1995: 321-362.

Heim, I. 1982. The Semantics of Definite and Indefinite Noun Phrases. Ph.D. dissertation, University of Massachusetts-Amherst.

Kamp, H. 1981. A Theory of Truth and Semantic Interpretation. Reprinted in J. Groenendijk, T.M.V. Jansen \& M. Stokhof, eds. 1984. Truth, Interpretation and Information, GRASS 2, Dordrecht: Foris.

Lewis, D. 1975. "Adverbs of Quantification". In E. Keenan, ed., Formal Semantics of Natural Languages, 3-15. Cambridge:Cambridge University Press.

LinK, G. 1983. The Logical Analysis of Plurals and Mass Terms: a Lattice Theorectical Approach. In R. Bauerle, C. Schwarze, \& A. Von SteCHow, eds. Meaning, Use and Interpretation of Language. Berlin: de Gruyter.

Matthewson, L. 2001 Quantification and Cross-Linguistic Variation. Natural Language Semantics 9: 145-189.

Montague, R. 1973. The Proper Treatment of Quantification in Ordinary English. In R. Thomason, ed. [1974] Formal Philosophy, Selected Papers of Richard Montague: 247-270. New Haven: Yale University Press.

MülLER, A. 2000. Sentenças genericamente quantificadas expressões de referência a espécies no português brasileiro. In Weerle, A. \& Ji-Young KIM (eds). The Proceedings of the SULA: The Semantics of Under-Represented Languages iin Américas, UMOP 25: 72-80. Amherst, MA: GLSA, The University of Massachussets.

Müller, A. 2001. "Genericity and the Denotation of Common Nouns in Brazilian Portuguese" in Cadernos de Estudos Lingüísticos 39: 141-158. 
Muller, Negrão \& Gomes: “Todo” em Contextos Coletivos e Distrib. 95

Negrão, E. V. 2002. Distributividade e Genericidade nos Sintagmas Introduzidos por Cada e Todo. Revista do GEL, número especial: 187204.

Partee, B. 1995. Quantificational Structures and Compositionality. In E. Bach, E. Jelinek, A. Kratzer \& B. Partee, eds. 1995: 541-618.

Schwarzchild, R. 1986. Pluralities. Dordrecht: Kluwer.

Quadros Gomes, A. P. 2004. Todo, Cada e Qualquer: Exigências sobre a Denotação Nominal e Verbal. Dissertação de Mestrado, Universidade de São Paulo.

Taub, A. 1989. Aktionsarten and All. In E. Bach, A. Kratzer \& B. Partee Papers on Quantification. UMOP: UMass-Amherst: Mass.

Vendler, Z. 1967. Linguistics in Philosophy. Cornell: University Press. 